Revista do Departamento de Geografia
Universidade de São Paulo
www.revistas.usp.br/rdg

\title{
Proposição de Corredor Ecológico entre duas Unidades de Conservação na Região Metropolitana de Sorocaba
}

\author{
Ecological Corridor Proposal Between Two Conservation \\ Units in the Sorocaba Metropolitan Region
}

\author{
Renan Angrizani de Oliveira \\ Universidade de Sorocaba \\ renan_angrizani@hotmail.com \\ Darllan Collins da Cunha e Silva \\ Universidade Estadual "Júlio de Mesquita Filho" \\ darllanamb@yahoo.com.br \\ Vanessa Cezar Simonetti \\ Universidade Estadual "Júlio de Mesquita Filho" \\ va_simoneti@hotmail.com \\ Eduardo Augusto Braga Stroka \\ Universidade de Sorocaba \\ eduardo.stroka@gmail.com \\ Débora Zumkeller Sabonaro \\ Universidade de Sorocaba \\ debora.sabonaro@prof.uniso.br
}

Resumo: Os corredores ecológicos possuem a importante função de permitir que os animais transitem com segurança de um fragmento florestal ao outro, favorecendo a dispersão de sementes e manutenção dos serviços ecossistêmicos prestados aos seres humanos. O presente estudo propôs um corredor ecológico ligando o Parque Natural Municipal Corredores de Biodiversidade à Floresta Nacional de Ipanema, através do uso de geoprocessamento para o cálculo da direção do fluxo utilizando o modelo do algoritmo Deterministic (D8) para selecionar o melhor percurso em função do menor custo para sua implantação. Verificaram-se diferentes classes de uso do solo e cobertura vegetal ao longo do corredor ecológico, o qual possui uma extensão de aproximadamente $14,3 \mathrm{~km}$ e área total de 270 ha, dos quais cerca de 19,4\% do corredor ecológico encontra-se em áreas de APP's, isto é, protegida legalmente, o que facilitaria a manutenção e criação deste e praticamente não está inserido em áreas urbanas $(0,8 \%)$, porém $13,8 \%$ do mesmo se encontra em propriedades agrícolas, o que necessitaria de uma fiscalização constante para sua preservação. Constatou-se que as técnicas de geoprocessamento são importantes ferramentas na criação e manutenção dos corredores ecológicos e, ainda, serve de suporte no desenvolvimento de políticas públicas que buscam garantir a sustentabilidade destas unidades de conservação e suas conexões.

Palavras-Chave: Geoprocessamento; Fluxo Gênico; Conexão de Fragmentos; Análise Espacial.
Abstract: Ecological corridors have the important function of allowing animals transiting safely from a forest fragment to another, favoring the dispersal of seeds and maintenance of ecosystem services to humans. The present study has proposed an ecological corridor connecting the Parque Natural Municipal Corredores de Biodiversidade to the Floresta Nacional de Ipanema, through the use of geoprocessing to calculate the flow direction using the algorithm model Deterministic (D8) to select the best route due to the lower cost for its implementation. It was verified different land use and vegetation cover along the ecological corridor, which has a length of approximately $14.3 \mathrm{~km}$ and a total area of $270 \mathrm{ha}$, of which around $19.3 \%$ of the ecological corridor is located in APP's areas, that is already legally protected, which would facilitate the maintenance and creation of this and practically is not inserted in urban areas (0.8\%), but $13.8 \%$ of it is in agricultural land, which require constant supervision for preservation. It was observed that the geoprocessing techniques are important tools in the creation and maintenance of ecological corridors and support the development of public policies that seek to ensure the sustainability of these conservation units and their connections.

Keywords: Geoprocessing; Gene flow; Fragments Connection; Spatial Analysis. 


\section{INTRODUÇÃO}

Os corredores ecológicos (CE) são importantes ferramentas para a conservação da flora e fauna, servindo para ligar Unidades de Conservação (UC's) isoladas, devido aos efeitos da fragmentação florestal, proveniente da expansão urbana decorrentes do crescimento populacional desordenado (SEOANE et al., 2010; UMEDA et al., 2015).

Todavia, é de extrema importância e urgência a implementação de corredores ecológicos para evitar o processo de fragmentação florestal que é bastante intenso no interior do Estado de São Paulo e que, conforme Rezende et al., (2011), embora este processo possa ser natural, vem se agravando drasticamente devido as ações antrópicas.

O processo de fragmentação florestal é responsável pela influência na composição genética das populações, reduzindo a variabilidade genética e consequentemente acarretando a perda da capacidade adaptativa das espécies, podendo até mesmo ocasionar a extinção por isolamento. Portanto, tendo em vista a manutenção da biodiversidade e, por conseguinte, a sobrevivência da fauna, flora e diversos serviços ecossistêmicos para a sociedade é necessário a implementação de estruturas com a finalidade de conexão dos fragmentos (MELO et al., 2014).

Diante do exposto, ressalta-se a capacidade dos CE de servir de zona de transição para as espécies presentes no Parque Natural Municipal Corredores de Biodiversidade (PNMCBio) e a Floresta Nacional de Ipanema (Flona de Ipanema), o qual permitirá que os animais transitem com segurança de um fragmento florestal ao outro, além de fornecer adequadas condições ambientais para a reprodução e sobrevivência dos indivíduos, garantindo o fluxo gênico entre estas populações e favorecendo que haja dispersão das sementes para a regeneração natural da floresta (LOURENÇO et al, 2014; MELO et al., 2014).

Desta forma, dentre os diversos serviços ecossistêmicos desempenhados para a população humana, destaca-se a preservação da disponibilidade de água, auxiliando na recarga dos recursos hídricos e retendo alguns gases nocivos à saúde humana, portanto, reduzindo os problemas de saúde relacionados à má qualidade do ar, contribuindo para a melhoria da qualidade de vida da população (LOURENÇO et al., 2014).

Para garantia da sustentabilidade do meio ambiente no Brasil, foi instituída a Lei $n^{\circ}$ 9.985, de 18 de julho de 2000, que trata do Sistema Nacional de Unidades de Conservação (SNUC), o qual é um dos mais sofisticados modelos de conservação do mundo. Esta dispõe de um conjunto de unidades de conservação nas esferas federais, estaduais e municipais, tendo sido concebido a fim de melhorar a administração e planejamento das Unidades de Conservação (UC). Ainda, de acordo com o Art. 25 "as unidades de conservação, exceto Área de Proteção Ambiental e Reserva Particular do Patrimônio Natural, devem possuir uma zona de amortecimento e, quando conveniente, corredores ecológicos que também estão previstos" (BRASIL, 2000).

A fim de permitir uma melhor avaliação espacial, Silva et al. (2011), Guirao et al. (2012) e Sales et al. (2016) destacam o uso de técnicas de geoprocessamento como uma ferramenta importantíssima para análise espacial e, por conseguinte, fornecimento de informações para a tomada de decisão. Nesse sentido, permitem avaliar as propriedades mais favoráveis à formação de fragmentos, contribuindo significativamente na evolução das práticas ambientais e na criação de políticas públicas voltadas para a manutenção e recuperação da biodiversidade e gestão racional dos recursos naturais (LINDENMAYER et al., 2008).

Desta forma, visando à conservação da biodiversidade presente na Região Metropolitana de Sorocaba (RMS), através da proposta de um corredor ecológico unindo duas importantes UC's da região, este trabalho objetivou a identificação do melhor caminho para instalação de um CE a partir de imagens matriciais de custos, que representam algum fator ou combinação de fatores que afetam o deslocamento da biota pelo corredor ecológico, tais como o uso do solo e cobertura vegetal, declividade do terreno e Áreas de Preservação Permanente (APP). Para determinar o melhor caminho para a instalação do CE foi utilizado o modelo do algoritmo Deterministic (D8) para o cálculo da direção do fluxo considerando o trecho que apresentasse o menor custo calculado a partir de pesos atribuídos as imagens matriciais em função da dificuldade para a implantação do CE. 


\section{METODOLOGIA}

A área de estudo compreende a Região Metropolitana de Sorocaba que engloba 22 municípios paulistas e possui uma população estimada em 2012 de 1.726.409, abrigando 1,4\% da população do Estado de São Paulo (LOURENÇO et al., 2015). A vegetação primária na RMS é caracterizada por floresta ombrófila densa, estando entre os domínios de Mata Atlântica e Cerrado (SALLES et al., 2008). Nesta Região Metropolitana estão inseridas as Unidades de Conservação objetos deste estudo, sendo elas o Parque Natural Municipal Corredores de Biodiversidade (PNMCBio) que está localizado no município de Sorocaba, com uma área total de aproximadamente 63 ha (COELHO et al., 2016), e também a Floresta Nacional de Ipanema (Flona de Ipanema), localizada nos municípios de Araçoiaba da Serra, Capela do Alto e Iperó, com área territorial de 5069,73 ha, segundo o plano de manejo realizado pelo ICMBio.

Para a proposta de interligação da Flona de Ipanema ao PNMCBio foram considerados fatores como o uso do solo e sua cobertura vegetal, as áreas de preservação permanente e a declividade entre essas duas Unidades de Conservação, devido a facilidade e agilidade de obtenção desses dados por sensores remotos. Para isso, adaptou-se a metodologia proposta por Louzada et al. (2012), baseada na técnica de pesos de menor custo.

O mapa de uso do solo e cobertura vegetal entre essas duas UC foi gerado a partir da análise das imagens de satélite multiespectrais ortorretificadas geradas pelo Satélite Landsat 8 sensor TM, de órbita/ponto 219/76, obtidas em 02 de maio de 2015, com resolução espacial de 30 metros. Para o tratamento e análise dessas imagens, foi utilizado o método de classificação supervisionada multivariada de Máxima Verossimilhança (MAXVER) presente no software ArcGIS 10.1.

$\mathrm{Na}$ classificação supervisionada, o analista seleciona as amostras de treinamentos representativas das classes a serem mapeadas, sendo que o agrupamento (ou clustering) é feito automaticamente pelo sistema, o qual identifica as nuvens de pixels que apresentam respostas espectrais semelhantes às amostras selecionadas, no caso do classificador paramétrico MAXVER, este classifica os agrupamentos de pixels considerando a ponderação das distâncias entre as médias dos níveis digitais de classe definida na seleção (LILLESAND et al., 2004).

As classes do mapa de uso do solo e cobertura vegetal da área de estudo foram divididas em pastagens, matas (área florestal), hidrografia, áreas urbanas, uso agrícola e reflorestamento, de acordo com os níveis I e II presentes no Manual Técnico de Uso da Terra (IBGE, 2013). Além disso, foram identificadas a Flona de Ipanema e o PNMCBio a partir de limites já estabelecidos e disponibilizados, respectivamente, pelo ICMBio e Prefeitura Municipal de Sorocaba.

Para o processamento das imagens do Landsat 8, foi gerada uma imagem falsa cor com a composição das bandas nos comprimentos de ondas do infravermelho próximo, infravermelho médio e vermelho respectivamente. Essa composição destaca a vegetação e os corpos hídricos dos demais tipos de usos e, portanto, facilita a extração desses usos do solo para compor o mapa de uso e ocupação do solo e cobertura vegetal (FLORENZANO, 2002).

As áreas urbanas, bem como as áreas agrícolas e reflorestamento foram extraídas manualmente sobre uma composição colorida das imagens do Landsat 8 , as quais foram identificadas através das imagens do software Google Earth Pro 7.1. Enquanto que, as demais áreas foram classificadas como pastagens. Todavia, para maior confiabilidade dos resultados, foram realizadas duas expedições nos dias 27 de março de $2016 \mathrm{e}$ 10 de abril de 2016 para confirmação das classes de uso do solo e cobertura vegetal identificadas, neste processo foi utilizado um GPS de navegação da marca Garmin modelo Etrex Vista para navegação e locomoção na área estudada.

Foram utilizados dados topográficos do SRTM (Shuttle Radar Topographic Mission) para gerar um Modelo Digital de Elevação (MDE) da área de estudo por meio de uma interpolação dos valores altimétricos pelo modelo de triangulação de Delaunay através da ferramenta TIN (Triangulated Irregular Network) do ArcGIS 10.1. A partir desse plano de informação foi gerado o mapa de declividade da área.

As áreas de preservação permanentes (APP's) foram obtidas utilizando a ferramenta buffer do ArcGIS 10.1 para calcular as distâncias das margens dos cursos de água previstas em lei (FELGUEIRAS, 2001). A malha hidrográfica utilizada no presente estudo foi vetorizada a partir de cartas planialtimétricas de 1979 disponibilizadas pelo Instituto Geográfico Cartográfico (IGC) na escala 1:10.000. 
Para a geração do corredor ecológico, primeiramente, foram geradas imagens matriciais de custos, que representam algum fator ou combinação de fatores que afetam o deslocamento da biota pelo corredor ecológico. Para estes fatores atribui-se pesos baseados na metodologia proposta por Louzada et al. (2012) que busca impedir ou limitar a passagem do CE por áreas não desejáveis como áreas edificadas e estradas. Os pesos variam de 1 a 100 , sendo atribuídos pesos mais elevados às classes de fatores que não são favoráveis à passagem da fauna, gerando assim, um mapa de custo cujas classes com maiores pesos teriam maiores custos para a implantação do CE.

O mapa das áreas de preservação permanente (APP's) da área de estudo foi dividido em duas classes para atribuição dos pesos. Para a classe de APP's foi atribuído o peso igual a 1, tendo em vista que o objetivo da rota é priorizar a passagem da fauna pelas APP's, enquanto que, para as demais áreas, foi atribuído à classe o peso 100, ou seja, onde as rotas seriam menos desejáveis.

O mapa de declividade da área de estudo foi dividido em três classes para a atribuição dos pesos: agricultável mecanicamente para áreas com declividade menor que $20^{\circ}$ com peso igual a 100 ; uso restrito com declividade entre $20^{\circ}$ à $45^{\circ}$ com peso igual a 50; e área de preservação permanente com declividade maior que $45^{\circ} \mathrm{com}$ peso igual a 1 . Como os terrenos com declividade mais suave (inferiores à $20^{\circ}$ ) são mais aptos para a mecanização na agricultura, estas áreas tiveram um custo maior para sua desapropriação, pois são áreas mais aptas para agricultura e dificilmente seriam disponibilizadas para a geração de um corredor ecológico, enquanto que, para as áreas com declividade superior a $45^{\circ}$ foi atribuído o menor peso, pois são APP's e adequadas para integrar o CE, uma vez que, o proprietário dessas terras é obrigado por lei a manter essa faixa de mata, o que facilitaria a implantação de um CE.

A partir do mapa de uso do solo e cobertura vegetal foram definidos os pesos para cada classe presente no mapa e justificados, conforme a Tabela 1.

Tabela 1: Pesos atribuídos às diferentes classes de usos do solo e cobertura vegetal.

\begin{tabular}{c|c|l}
\hline Classes & Pesos & \multicolumn{1}{c}{ Justificativas } \\
\hline $\begin{array}{c}\text { Área urbana e uso } \\
\text { agrícola }\end{array}$ & 100 & $\begin{array}{l}\text { Considerada como barreiras para a passagem do CE, recebendo o } \\
\text { custo extremo, além de sua aquisição para esta implantação ser muito } \\
\text { complexa. }\end{array}$ \\
\hline Pastagem & 50 & $\begin{array}{l}\text { São áreas que podem ser utilizadas para agropecuária e seria } \\
\text { necessário recuperá-la com plantio de espécies nativas. }\end{array}$ \\
\hline Matas & 1 & $\begin{array}{l}\text { São áreas plantadas, em sua maioria com objetivo econômico, sendo } \\
\text { suprimida após alguns anos ficando a área desflorestada, deixando de } \\
\text { desempenhar sua função como CE, podendo ou não voltar a ser } \\
\text { florestada. }\end{array}$ \\
\hline Hidrografia & 1 & $\begin{array}{l}\text { São áreas adequadas para integrar o CE. } \\
\text { PNMenta áreas adequadas para integrar o CE, sendo o lugar de } \\
\text { preservação. Não é considerado como barreira, pois há presença de } \\
\text { matas marginais. }\end{array}$ \\
\hline Flona de Ipanema & 1 & $\begin{array}{l}\text { Unidade de conservação de proteção integral, com Área de } \\
\text { Preservação Permanente. }\end{array}$ \\
\hline
\end{tabular}

Fonte: Adaptado de Louzada et al. (2012).

Após a atribuição dos pesos, as imagens matriciais de custo geradas foram multiplicadas pelo seu respectivo peso, o qual foi calculado a partir do método de Análise Hierárquica de Processos (AHP) proposto por Saaty (1991) e aplicado por Louzada et al. (2012). Os pesos calculados para cada mapa de custo das APP's; declividade; uso do solo e cobertura vegetal foram respectivamente: 0,2605; 0,1061 e 0,6334. 
Posteriormente, as imagens resultantes foram somadas para gerar um mapa de Custo Total (CT) de acordo com a Equação 1:

$$
C T=0,2605 \times A P P+0,1061 \times \text { Decliv }+0,6334 \times U s o
$$

(Equação 1)

Onde:

$C T$ é a imagem matricial do custo total;

$A P P$ é a imagem matricial do custo de APP's;

Decliv é a imagem matricial do custo de declividade;

Uso é a imagem matricial do custo de uso do solo e cobertura vegetal.

Para traçar o melhor caminho, o qual representa os menores custos atribuídos entre as duas Unidades de Conservação, utilizou-se a ferramenta Flow Direction do módulo Hydrology do ArcGIS 10.1 para calcular o caminho mais curto a partir do algoritmo Deterministic (D8). Nesse modelo a obtenção da direção de fluxo em cada pixel pode ser realizada por procedimentos automatizados, o qual atribui o sentido da direção de um pixel para um de seus oito vizinhos com base na diferença do valor digital ponderado pela distância entre eles. Como resultado, a cada pixel é atribuído um número indicativo de uma das oito direções de fluxo possíveis. Esta função utiliza as imagens matriciais de distância e direção de custo para determinar uma rota de custo efetivo entre a origem e o destino. Dessa forma, foi traçado o corredor interligando as duas UC's.

A largura do corredor foi definida utilizando a Resolução CONAMA 09/96 que determina as regras para o cálculo da largura de corredores ecológicos. Segundo BRASIL (1996), a largura do corredor ecológico corresponde a $10 \%$ do seu comprimento total, porém optou-se por trabalhar com a largura mínima que é de $100 \mathrm{~m}$, pois o comprimento do corredor ecológico proposto é de aproximadamente $14,3 \mathrm{~km} \mathrm{e} 10 \%$ desse comprimento como largura mínima tornaria o corredor inviável. Todavia, como em quase todo o trecho do corredor segue-se algum curso de água e a resolução do CONAMA 09/96 estabelece que quando em faixas marginais ao curso de água, a largura mínima se fará em ambas as margens do rio, ficou estabelecido que a largura mínima do corredor proposto fosse de 200m (BRASIL, 1996).

\section{RESULTADOS E DISCUSSÃO}

As unidades de conservação selecionadas foram prioritárias por estarem localizadas em uma área de grande aglomeração urbana dentro da RMS, conferindo a essa região um grande potencial poluidor, provenientes principalmente da queima de combustíveis fósseis em veículos e atividades industriais. Ainda é possível verificar os diferentes usos do solo na área de estudo (Figura 1) e identificar um alto grau de fragmentação da vegetação. Todavia, as alterações no uso e ocupação do solo implicam em diversos impactos ambientais; assim, a proposição de um CE é uma medida de contenção dos danos ambientais provenientes das atividades antrópicas.

Após análise da declividade apresentada na Figura 2, foi possível observar declividades mais acentuadas na região da Flona de Ipanema, enquanto que, na região do PNMCBio, as declividades são mais amenas. De acordo com Silva et al. (2016a), as áreas que apresentam altas declividades são mais suscetíveis à erosão hídrica, sendo prioritárias em termos de conservação, por isso, áreas com declividades superiores a $45^{\circ}$ são consideradas APP's.

A erosão ocasionada pela alta declividade pode interferir na qualidade da água dos recursos hídricos por meio do carreamento de material particulado provenientes da desagregação de partículas de solo, bem como no aumento da matéria orgânica, o que pode desencadear um processo de eutrofização do ambiente aquático (SILVA et al., 2016b). Porém, quando essas áreas são conservadas, podem servir de abrigo e de corredores para locomoção de espécies, uma vez que, o difícil acesso dificulta e às vezes inviabiliza a intervenção antrópica nesses locais, o que favorece a conservação da biodiversidade por abrigar e proteger a fauna silvestre e a flora nativa (DOBROVOLSKI et al., 2006) 


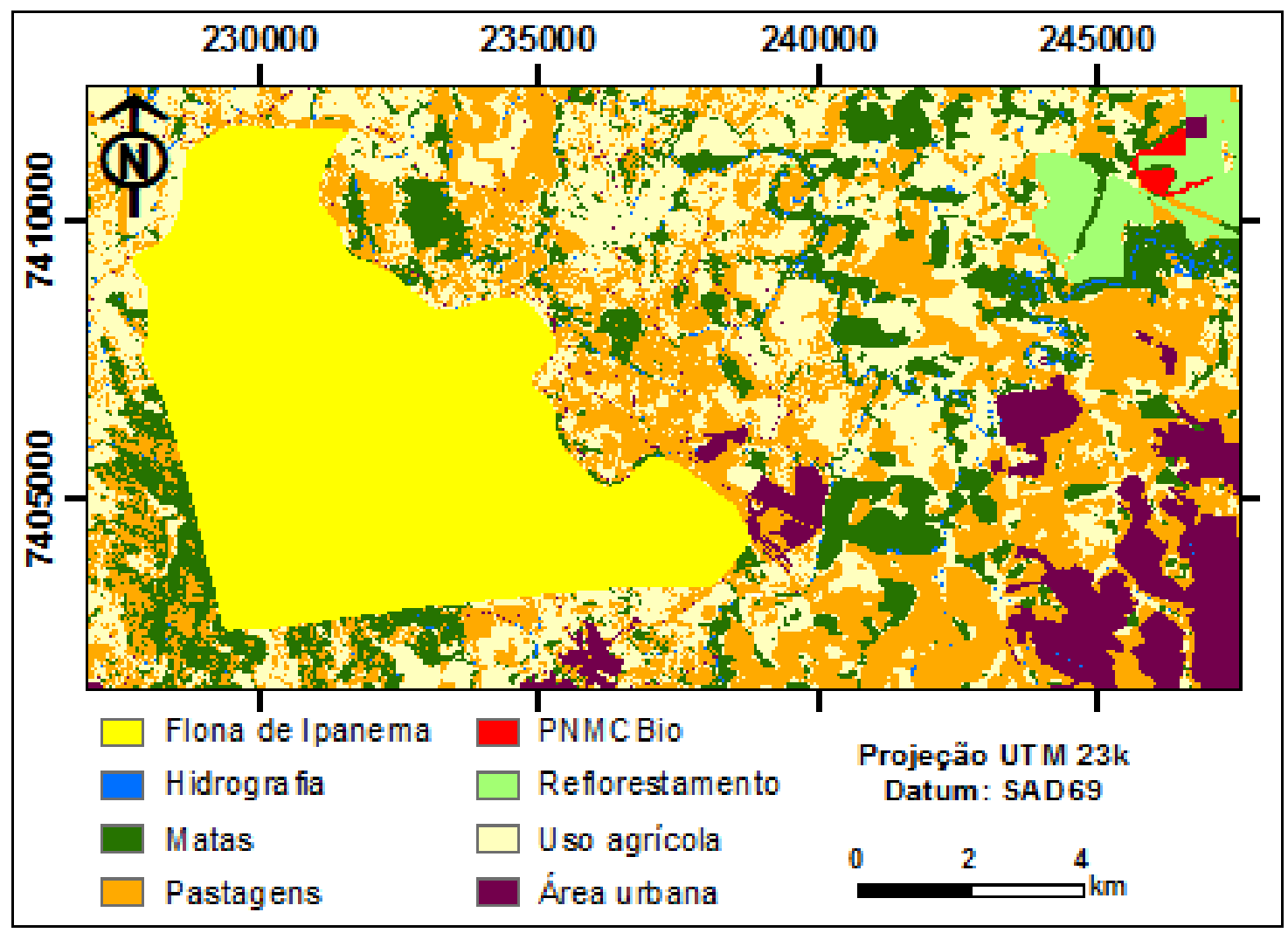

Figura 1: Mapa de uso do solo e cobertura vegetal da área de estudo.

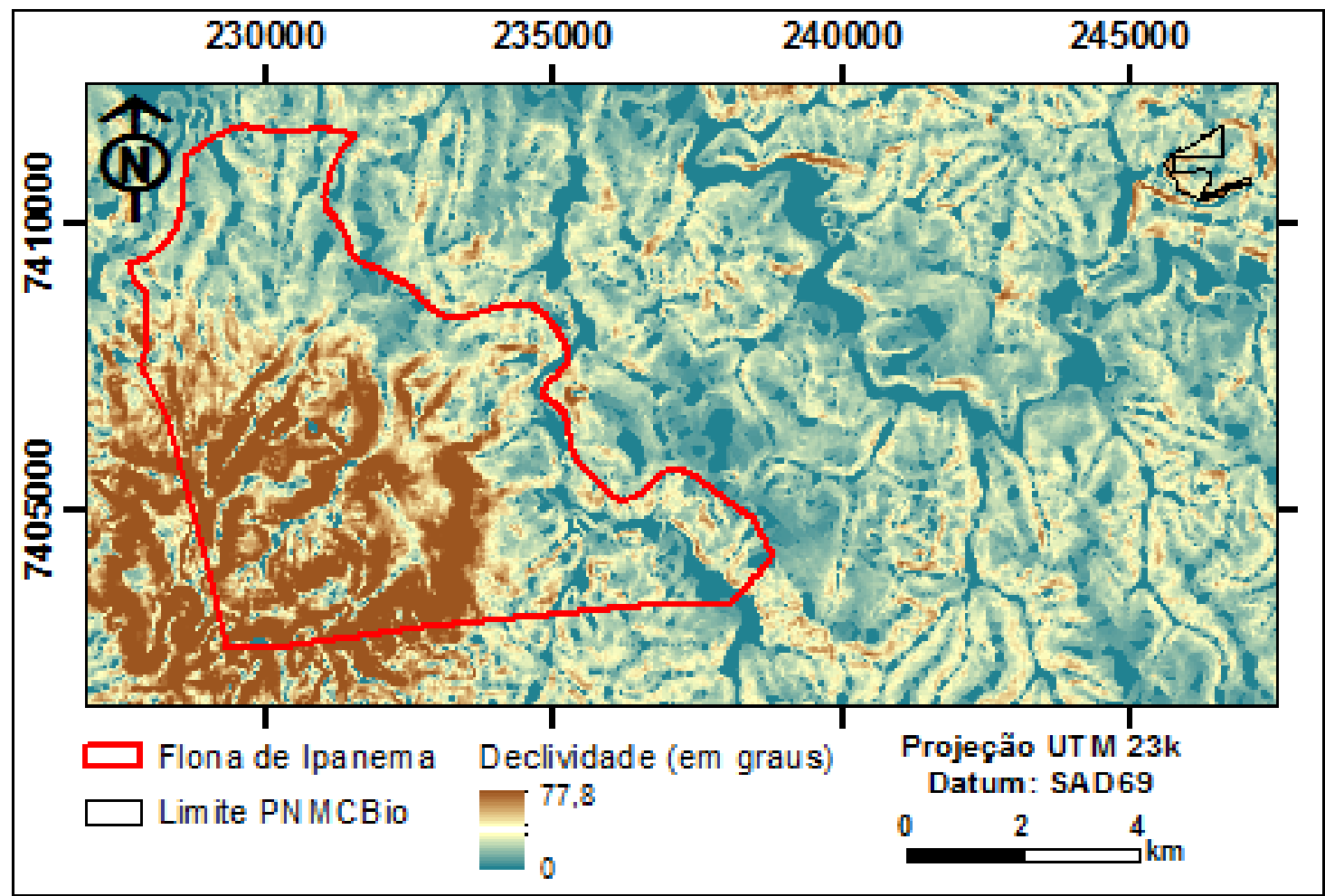

Figura 2: Mapa da declividade da área de estudo.

Posteriormente, foram analisados os recursos hídricos e suas margens para definir as áreas de APP's, bem como áreas com declividades acima de $45^{\circ}$ classificadas como de preservação permanente, isto é, não passíveis de intervenção. Logo, foi possível gerar o mapa das APP's presentes na área de estudo (Figura 3), onde foi possível observar as aglomerações de APP's na Flona de Ipanema. Tal fato deve-se principalmente às características do terreno que apresentam alta declividade. 
Por apresentar diferentes tipologias florestais, a área possui vasta biodiversidade catalogada em virtude de inúmeros estudos científicos que foram compilados por Smith et al. (2014), constatando a presença de diversas espécies somente no município de Sorocaba, distribuídas em categorias, sendo 555 espécies vegetais, 612 espécies animais entre mamíferos e zooplânctons, além de aves (280), aracnídeos (58), insetos (75), entre outras.

Entretanto, a Flona de Ipanema, segundo o IBAMA (2003), contempla 21,6\% da riqueza total do Estado de São Paulo, corroborando com importância da implantação do CE no sentido de auxiliar na manutenção e preservação da biodiversidade presente na região, das quais algumas espécies encontram-se ameaçadas de extinção. Além disso, aproximadamente $80 \%$ do corredor ecológico proposto encontra-se na Zona de Amortecimento da Flona de Ipanema, o que reforça ainda mais a proposta para a geração de um corredor ecológico para essa região.

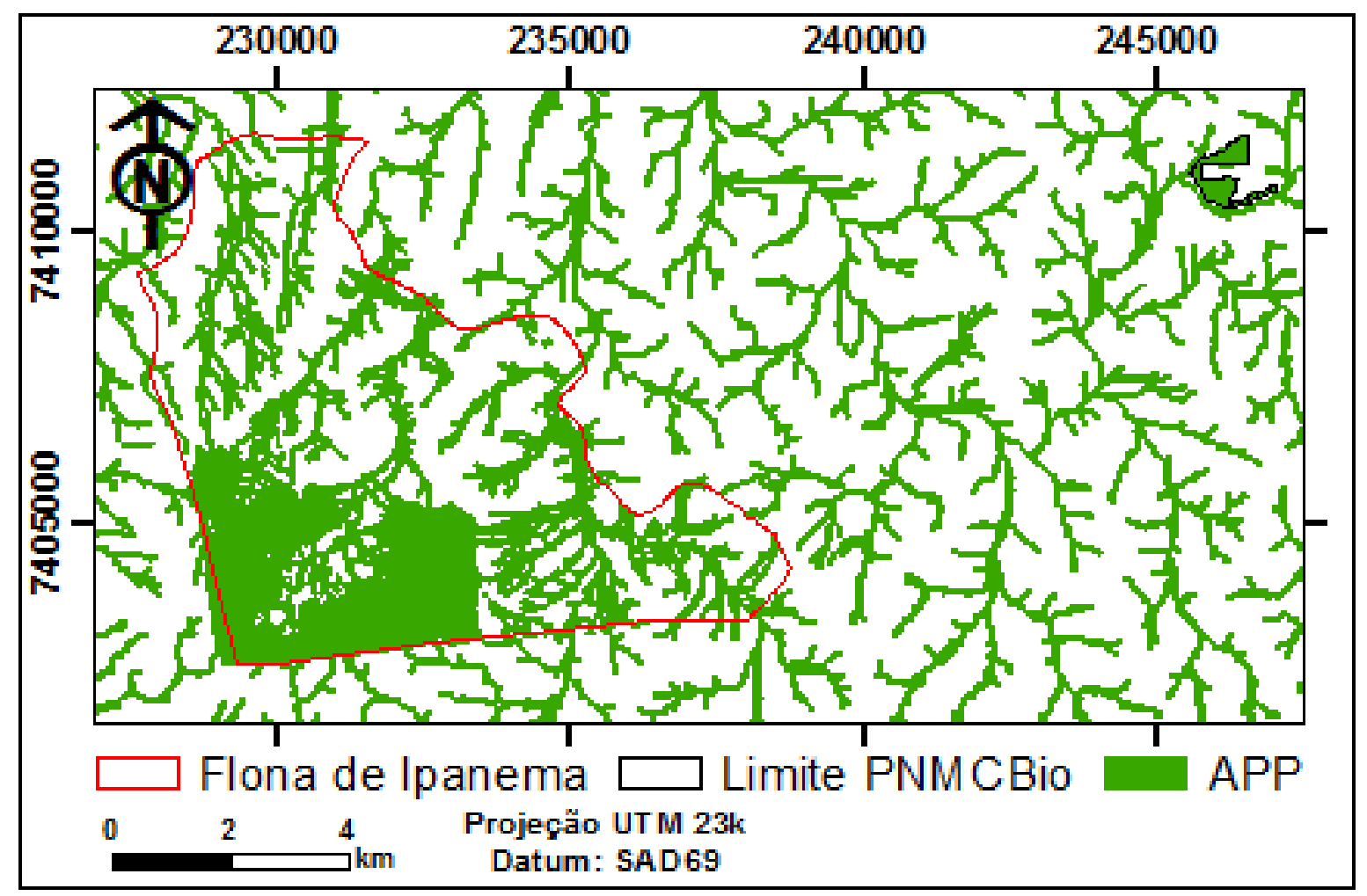

Figura 3: Mapa das APP's da área de estudo.

Após a geração dos planos de informação para a área de estudo, foi possível estabelecer o melhor caminho para a implantação do CE proposto para interligar a Flona de Ipanema ao PNMCBio, com base nos pesos atribuídos para cada classe do uso do solo e cobertura vegetal, declividades e APP's.

O caminho preferencial do CE foi gerado automaticamente com auxílio da ferramenta Flow Direction do módulo Hydrology presente no software ArcGis 10.1, conforme é apresentada na Figura 4.

Diante do exposto, foi possível constatar que a distribuição do CE é acompanhada de diferentes classes de uso do solo e cobertura vegetal ao longo de sua extensão de aproximadamente $14,3 \mathrm{~km}$, tendo área total de 269,9 ha como pode ser constatado na Tabela 2.

Constatou-se mediante análise da Tabela 2, que o percurso do corredor ecológico praticamente não percorre áreas urbanas, porém há uma alta porcentagem inserida em propriedades agrícolas, que necessitariam de uma fiscalização constante para sua preservação. Esta situação poderia ocasionar um alto custo para desapropriação dessas áreas pelo governo, para que essas áreas viessem a compor o CE (LOUZADA et al., 2012). Dos 153,8 ha de matas, aproximadamente 52,3 ha dessas áreas propostas para o corredor ecológico encontram-se em áreas de APP's, isto é, 19,4\% da área já está protegida legalmente, o que facilitaria a manutenção desse corredor.

A Figura 5 destaca o uso do solo e cobertura vegetal do corredor ecológico proposto, onde é possível observar a predominância da classe de matas e a quase ausência de edificações antrópicas, que estão classificadas nesse estudo como áreas urbanas. 
É possível observar na Figura 5 que há áreas de APP's que não apresentam matas ciliares desempenhando suas funções ecológicas e, portanto, estas seções dos cursos de águas estão desprotegidas e devem ser recuperadas tanto por lei quanto pelas funções ecológicas que desempenham (VOGEL et al., 2009).

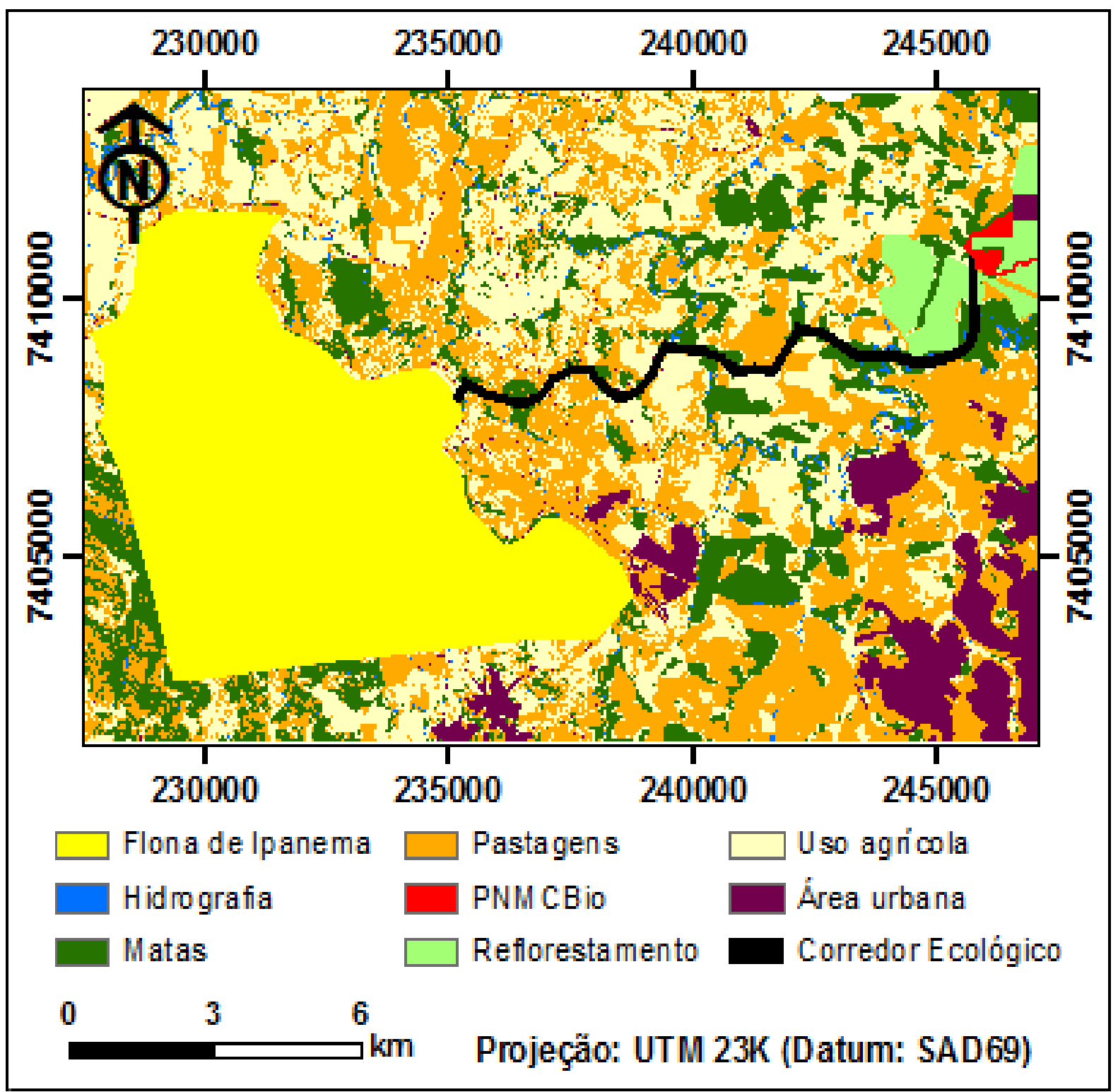

Figura 4: Mapa de uso do solo e cobertura vegetal com o CE proposto.

Tabela 2: Distribuição das classes de uso do solo e cobertura vegetal no traçado do CE.

\begin{tabular}{ccc}
\hline Classes & Área (ha) & \% do total \\
\hline Uso agrícola & 37,3 & $13,8 \%$ \\
Pastagens & 62,6 & $23,2 \%$ \\
Matas & 153,8 & $57,0 \%$ \\
Área Urbana & 2,2 & $0,8 \%$ \\
Reflorestamento & 14 & $5,2 \%$ \\
\hline
\end{tabular}




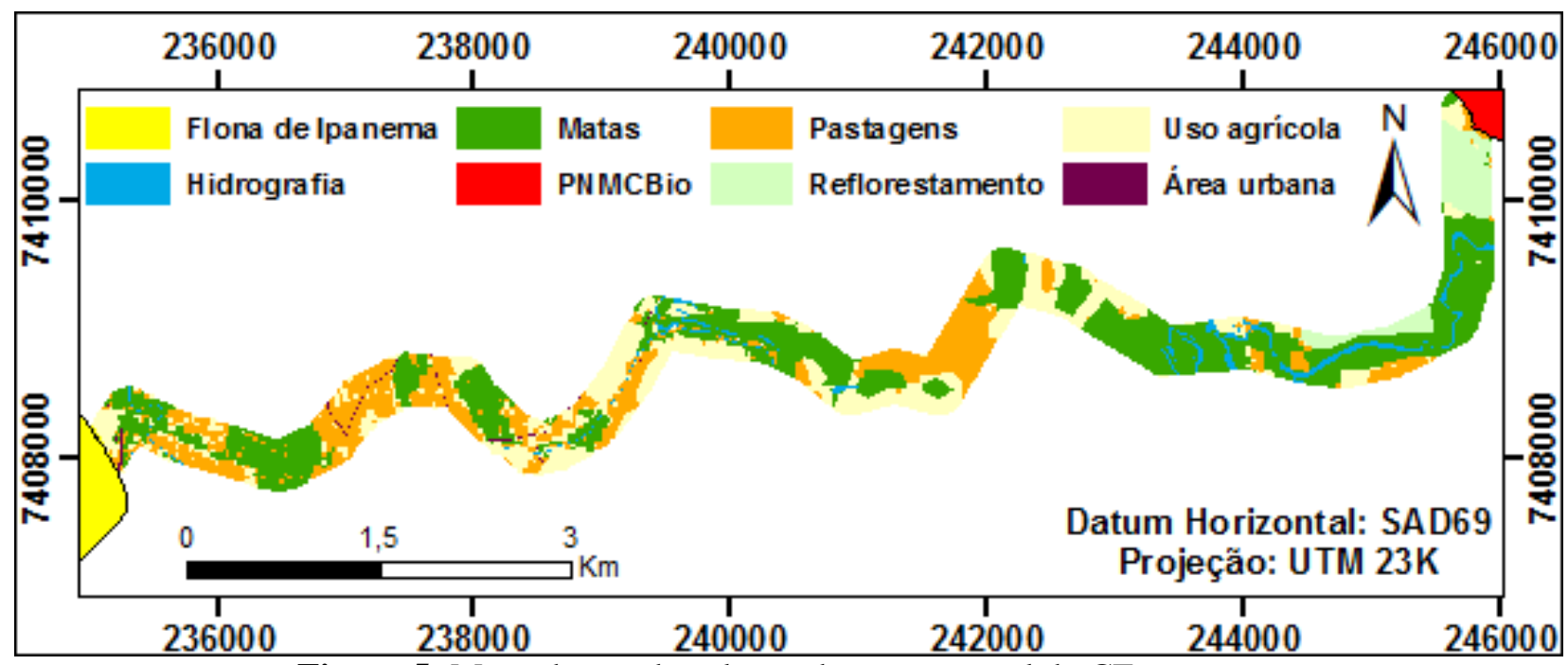

Figura 5: Mapa de uso do solo e cobertura vegetal do CE proposto.

Ainda conforme Meira et al. (2016), para a conservação e manutenção do corredor ecológico proposto, devem ser promovidas atividades como agricultura e pecuária sustentáveis, de modo a conter a degradação do solo, mantendo a ciclagem de nutrientes e evitando a deterioração dos corpos hídricos.

Também devem ser promovidos cursos que enfoquem técnicas de adequação ambiental para a regularização e averbação de Reserva Legal para proteção das APP's, pois são áreas protegidas por lei e que podem favorecer a criação do corredor ecológico, além de apresentarem o menor custo e maior facilidade para implantação do mesmo (MEIRA et al., 2016).

Além disso, Henriques e Negro (2007) enfatizam a importância do estímulo às atividades de ecoturismo e de turismo sustentável como forma de geração de renda para as comunidades locais, promovendo, desta forma, a manutenção dessas áreas através do incentivo ao comércio de produtos ambientalmente sustentáveis, uma vez que, atividades como essas favorecem o fortalecimento da relação homem-natureza, tanto da população local, quanto dos visitantes dessas áreas.

\section{CONCLUSÕES}

Os corredores ecológicos irão estender e reforçar o modelo atual das Unidades de Conservação, garantindo sua sustentabilidade bem como melhorar sua regeneração. Para a Região Metropolitana de Sorocaba a implementação do CE é de extrema importância, pois além de servir de zona de transição para as espécies presentes no PNMCBio e a Flona de Ipanema, permitirá que os animais transitem com segurança de um fragmento florestal ao outro, garantindo o fluxo gênico entre estas populações, favorecendo que haja dispersão das sementes para a regeneração natural da floresta. Além disso, este garantirá em boa parte de sua extensão a preservação de matas ciliares, que já são preservadas por lei, porém com faixa menor que a proposta na implantação do CE.

Os resultados obtidos no estudo, demonstraram que o $\mathrm{CE}$ proposto com extensão de aproximadamente $14,3 \mathrm{~km}$ e área total de 270 ha, possui seu trajeto favorável a implantação, visto que cerca de 19,4\% encontra-se em APP's, que são áreas protegidas legalmente, o que facilitará sua criação e manutenção. Este ainda, praticamente não percorrerá áreas de difícil implantação devido a ocupação antrópica, como áreas urbanas, onde o percurso proposto ocupa apenas $0,8 \%$, e propriedades agrícolas que representa $13,8 \%$ da extensão do CE, e necessitará de uma fiscalização constante para sua preservação.

As técnicas de geoprocessamento utilizadas demonstraram ser um importante instrumento de apoio na elaboração de corredores ecológicos e, portanto, servem para o desenvolvimento de políticas públicas que buscam garantir a sustentabilidade das UC's e suas conexões. 


\section{REFERÊNCIAS}

BRASIL. Ministério do Meio Ambiente, Conselho Nacional de Meio Ambiente, CONAMA. Resolução CONAMA nº 9, de 24 de outubro de 1996.

BRASIL. Lei Federal n. 9.985, de 18 de julho de 2000. Regulamenta o art. 225, § 1o, incisos I, II, III e VII da Constituição Federal, institui o Sistema Nacional de Unidades de Conservação da Natureza e dá outras providências. Presidência da República - Casa Civil, Brasília, DF, 18 jul. 2000.

COELhO, S.; CARDOSO-LEITE, E.; CASTELlO, A. C. D. Composição florística e caracterização sucessional como subsídio para conservação e manejo do PNMCBio, Sorocaba - SP. Ciência Florestal, Santa Maria, v. 26, n. 1, p. 331-344, 2016.

DOBROVOLSKI, R.; BOTH, R.; COELHO, I. P.; STOLZ, J. F.; SCHÜSSLER, G.; RODRIGUES, G. G.; GUERRA, T.; HARTZ, S. M. Levantamento de áreas prioritárias para a conservação da Floresta Nacional de São Francisco de Paula (RS, Brasil) e seu entorno. Revista Brasileira de Biociências, v. 4, n. 1/2, p. 7 $14,2006$.

FELGUEIRAS, C. A. Modelagem numérica de terreno. In: CÂMARA, G.; DAVIS, C.; MONTEIRO, A. M. V. Introdução à Ciência da Geoinformação. São José dos Campos: Instituto Nacional de Pesquisas Espaciais (INPE), 2001.

FLORENZANO, T. G. Imagens de Satélite para estudos ambientais. São Paulo: Oficina de Textos, 2002.

GUIRAO, Â. C.; FONSECA, M. F.; CASTELLANO, M. S. Problemática das inundações e sua relação com a situação das áreas de preservação permanente: visão do poder público e o uso de geoprocessamento. Revista do Departamento de Geografia, v. 24, p. 151-168, 2012.

HENRIQUES, J. H. P.; NEGRO, E. F. C. Turismo sustentável nos corredores ecológicos do estado do Espírito Santo. In: Instituto do Meio Ambiente e de Recursos Naturais Renováveis Corredores Ecológicos: experiência em planejamento e implantação. Ministério do Meio Ambiente, Secretaria de Biodiversidade e Florestas. Brasília, 2007.

IBAMA. Plano de Manejo: Floresta Nacional de Ipanema, Iperó. Ministério do Meio Ambiente, Brasília, 2003.

IBGE - Instituto Brasileiro de Geografia e Estatística. Manual Técnico de Uso da Terra. 3 ed. Rio de Janeiro: IBGE, 2013. 171 p.

LILLESAND, T. M.; KIEFER, R. W.: CHIPMAN, J. W. Remote Sensing and Image Interpretation. Nova York: John Wiley \& Sons, 2004.

LINDENMAYER, D. A et al. Checklist for Ecological Management of Landscapes for Conservation. Ecology Letter, v. 11, n. 1, p. 78-91, 2008.

LOURENÇO, R. W.; SILVA, D. C. C.; SALES, J. C. A. Elaboração de uma metodologia de avaliação de fragmentos de remanescentes florestais como ferramenta de gestão e planejamento ambiental. AMBIÊNCIA, v. 10, n. 3, p. 685-698, 2014.

LOURENÇO, R. W.; SILVA, D. C. C.; SAlES, J. C. A.; DE MEDEIROS, G. A.; OTERO, R. A. P. Metodologia para seleção de áreas aptas à instalação de aterros sanitários consorciados utilizando SIG. Ciência e Natura, v. 37, n. 4, p. 122-140, 2015.

LOUZADA, F. L. R. O.; DOS SANTOS, A. R.; DA SILVA, A. G.; DE OLIVEIRA, O. M.; DE OLIVEIRA G. G.; SOARES, V. P.; PELUZIO, J. B. E. Proposta de corredores ecológicos para interligação de parques estaduais utilizando geotecnologia, Espírito Santo (ES) - Brasil. Revista Geográfica Venezolana, v. 53, n. 2, p. 2, 239-254, 2012.

MEIRA, R. T.; SABONARO, D. Z.; SILVA, D. C. C. Elaboração de Carta de Adequabilidade Ambiental de uma pequena propriedade rural no município de São Miguel Arcanjo, São Paulo, utilizando técnicas de geoprocessamento. Engenharia Sanitária e Ambiental, Rio de Janeiro, v. 21, n. 1, p. 77-84, 2016.

MELO, A. T. O.; COELHO, A. S. G.; PEREIRA, M. F.; BLANCO, A. J. V.; FRANCESCHINELLI, E. V. High genetic diversity and strong spatial genetic structure in Cabralea canjerana (Vell.) Mart.(Meliaceae): implications to Brazilian Atlantic Forest tree conservation. Natureza \& Conservação, v. 12, n. 2, p. 129133, 2014. 
REZENDE, R. A.; PRADO FILHO, J. F.; SOBREIRA, F. G. Análise temporal da flora nativa no entorno de unidades de conservação-APA Cachoeira das Andorinhas e FLOE Uaimii, Ouro Preto, MG. Revista Árvore, v. 35, n. 3, p. 435-443, 2011.

SAATY, T. L. Método de Análise Hierárquica. São Paulo: McGraw-Hill Publisher, 1991. 367 p.

SALES, J. C. A.; SILVA, D. C. C.; ROMAGNANO, L. F. T.; BERTAGNA, R.; LOURENÇO, R.W. Avaliação do impacto ambiental causado pelas alterações espaço temporal do uso do solo e da cobertura vegetal utilizando o modelo das cadeias de markov. Ciência e Natura, v. 38, n. 1, p. 115-124, 2016.

SALLES, M. H. D.; CONCEIÇÃO, F. T.; ANGELUCCI, V. A.; SIA, R.; PEDRAZZI, F. J. M.; CARRA, T. A.; MONTEIRO, G.; SARDINHA, D.S.; NAVARRO, G. R. B. Avaliação simplificada de impactos ambientais na Bacia do Alto Sorocaba (SP). Revista de Estudos Ambientais, Sorocaba, v. 10, n. 1, p. 620, 2008.

SEOANE, C. E. S.; DIAZ, V. S.; SANTOS, T. L.; FROUFE, L. C. M. Corredores ecológicos como ferramenta para a desfragmentação de florestas tropicais. Pesquisa Florestal Brasileira, v. 30, n. 63, p. 207-216, 2010.

SILVA, D. C. C.; ALBUQUeRQUE FILHO, J. L.; SAlES, J. C. A.; LOURENÇO, R. W. Use of morphometric indicators as tools for assessment watershed. Revista Brasileira de Geografia Física, v. 9, n. 2,p. 627-642, 2016 a.

SILVA, D. C. C.; SALES, J. C. A.; ALBUQUERQUE FILHO, J. L.; LOURENÇO, R. W. Caracterização morfométrica e suas implicações no acúmulo de sedimentos em reservatórios: $\mathrm{O}$ caso da Represa Hedberg, Iperó/SP. Raega-O Espaço Geográfico em Análise, v. 36, p. 225-245, 2016 b.

SILVA, J. B.; GAlvínCIO, J. D.; BARRos CORRÊA, A. C.; SILVA, D. G.; MACHADO, C. C. C. Classificação Geomorfológica dos Estuários do Estado de Pernambuco (Brasil) com Base em Imagens do LANDSAT 5/TM. Revista Brasileira de Geografia Física, v. 4, n. 1, p. 118-133, 2011.

SMITH, W. S.; MOTA JUNIOR, V. D.; CARVALHO, J. L. Biodiversidade do município de Sorocaba. Sorocaba, SP: Prefeitura Municipal de Sorocaba, Secretaria do Meio Ambiente, 2014. 272 p.

UMEDA, C. Y. L.; SANTOS, T. H. L. D.; LASTORIA, G.; OLIVEIRA, A. P. G.; COUTINHO, H. L. D. C.; PARANHOS FILHO, A. C. Uso de sensoriamento remoto na identificação de corredores ecológicos: estudo de caso da Bacia Hidrográfica do Rio Formoso, Bonito, MS. Engenharia Sanitária e Ambiental, v. 20, n. 4, p. 551-557, 2015.

VOGEL, H. F.; ZAWADZKI, C. H.; METRI, R. Florestas ripárias: importância e principais ameaças. SaBios-Revista de Saúde e Biologia, v. 4, n. 1, p. 24-30, 2009. 